\title{
Rhesus Monkey
}

National Cancer Institute

\section{Source}

National Cancer Institute. Rhesus Monkey. NCI Thesaurus. Code C14233.

A pale brown macaque (Macaca mulatta) native to India, China, and other parts of Asia; often used in medical research. A medium-sized diurnal primate, the Macaca mulatta has a diet of plant material and insects that it can store in pouches in its mouth. The rhesus monkey has an inquisitive, destructive nature with a tendency to bite and pinch; captive breeds are used almost exclusively for medical research. The rhesus monkey has a long history in biomedical research owing to its relative ease in upkeep, most famously utilized in the study of the rhesus factor in human blood groups, the effects of space travel on humans, as well as being the first cloned and transgenic primate. 